\title{
Transcriptome Changes Reveal the Molecular Mechanisms of Humic Acid-Induced Salt Stress Tolerance in Arabidopsis
}

\author{
Joon-Yung Cha ${ }^{1, *}$, Sang-Ho Kang ${ }^{2}{ }^{(0)}$, Myung Geun Ji ${ }^{1}$, Gyeong-Im Shin ${ }^{1}$, Song Yi Jeong ${ }^{1}$, Gyeongik Ahn ${ }^{3}$, \\ Min Gab Kim ${ }^{4}$, Jong-Rok Jeon ${ }^{3}$ and Woe-Yeon Kim ${ }^{1,3, *}$
}

1 Division of Applied Life Science (BK21four), Plant Molecular Biology and Biotechnology Research Center, Research Institute of Life Sciences, Gyeongsang National University, Jinju 52828, Korea; mgj2930@gnu.ac.kr (M.G.J.); shin123@gnu.ac.kr (G.-I.S.); songyi123@gnu.ac.kr (S.Y.J.)

2 Genomics Division, National Institute of Agricultural Sciences, Rural Development Administration, Jeonju 54874, Korea; hosang93@korea.kr

3 Department of Agricultural Chemistry and Food Science \& Technology, Institute of Agriculture and Life Science, Gyeongsang National University, Jinju 52828, Korea; ahngi@gnu.ac.kr (G.A.); jrjeon@gnu.ac.kr (J.-R.J.)

4 College of Pharmacy and Research Institute of Pharmaceutical Science, Gyeongsang National University, Jinju 52828, Korea; mgk1284@gnu.ac.kr

* Correspondence: jycha@gnu.ac.kr (J.-Y.C.); kim1312@gnu.ac.kr (W.-Y.K.); Tel.: +82-55-772-1968 (J.Y.C. \& W.-Y.K.); Fax: +82-55-772-2631 (J.Y.C. \& W.-Y.K.)

Citation: Cha, J.-Y.; Kang, S.-H.; Ji, M.G.; Shin, G.-I.; Jeong, S.Y.; Ahn, G.; Kim, M.G.; Jeon, J.-R.; Kim, W.-Y. Transcriptome Changes Reveal the Molecular Mechanisms of Humic Acid-Induced Salt Stress Tolerance in Arabidopsis. Molecules 2021, 26, 782. https://doi.org/10.3390/

molecules 26040782

Academic Editor: Riccardo Spaccini Received: 31 December 2020

Accepted: 29 January 2021

Published: 3 February 2021

Publisher's Note: MDPI stays neutral with regard to jurisdictional claims in published maps and institutional affiliations.

Copyright: (c) 2021 by the authors. Licensee MDPI, Basel, Switzerland. This article is an open access article distributed under the terms and conditions of the Creative Commons Attribution (CC BY) license (https:/ / creativecommons.org/licenses/by/ $4.0 /)$.

\begin{abstract}
Humic acid (HA) is a principal component of humic substances, which make up the complex organic matter that broadly exists in soil environments. HA promotes plant development as well as stress tolerance, however the precise molecular mechanism for these is little known. Here we conducted transcriptome analysis to elucidate the molecular mechanisms by which HA enhances salt stress tolerance. Gene Ontology Enrichment Analysis pointed to the involvement of diverse abiotic stress-related genes encoding HEAT-SHOCK PROTEINs and redox proteins, which were up-regulated by HA regardless of salt stress. Genes related to biotic stress and secondary metabolic process were mainly down-regulated by HA. In addition, HA up-regulated genes encoding transcription factors (TFs) involved in plant development as well as abiotic stress tolerance, and down-regulated TF genes involved in secondary metabolic processes. Our transcriptome information provided here provides molecular evidences and improves our understanding of how HA confers tolerance to salinity stress in plants.
\end{abstract}

Keywords: arabidopsis; humic acid; salt stress; transcriptome analysis

\section{Introduction}

Humic acid is composed of a complex supramolecular association known as humic substances (HSs), which is produced by humification of organic matter such as peat, compost, and plants in soil environments [1]. Although HSs are amorphous and depend on their source of extraction from soil, partial polymeric structures can be identified containing diverse aromatic and aliphatic structures [2,3]. These physicochemical properties have not only prompted their agricultural use as soil amendments, but also as plant growth stimulators [3-5]. There is evidence that wheat seedlings directly take up and accumulate HA in tissues [6], suggesting that HA stimulates diverse transcriptional changes promoting the physiological and developmental processes of plants.

Salinity stress is one of the major abiotic stresses reducing crop yield, afflicting $20 \%$ of the total arable land worldwide [7]. Soil salinity affects the morphological, physiological, and biochemical processes of plants across all developmental stages, including seed germination, root and vegetative growth, and production of cereals and fruits [7]. High salt levels accompany additive cellular stresses such as ionic, osmotic, and oxidative stress in plants $[8,9]$. Ionic stress, mainly caused by $\mathrm{Na}^{+}$ions, is prevented by maintaining cellular 
ionic homeostasis, including levels of $\mathrm{Na}^{+}, \mathrm{K}^{+}$, and $\mathrm{Ca}^{2+}$ ions [8]. Various transporters localized in the plasma membrane and the tonoplast are directly involved in redistribution and compartmentation of ions. To protect against increases in osmotic potential, plants accumulate metabolites functioning as osmolytes, such as soluble sugars, glycine betaine, and proline [10]. Salt-induced oxidative stress in plants triggers membrane damage, and reactive oxygen species (ROS) are scavenged by antioxidant enzymes $[9,10]$. In promoting these responses, salinity stress turns on multiple genes, and drives multiple stress signaling networks and physiological mechanisms enhancing plant tolerance.

We found that HA enhances tolerance to excessive salt levels via post-transcriptional control of the HIGH-AFFINITY $\mathrm{K}^{+}$TRANSPORTER 1 in Arabidopsis [11]. Most recently, we also reported that HA drives global transcriptome changes, especially genes involved in response to heat including genes encoding HEAT-SHOCK PROTEINs (HSPs) [12], which are essential for acquiring thermotolerance in Arabidopsis [13]. Although numerous biological effects of HA and HSs have been reported in plants [5], the precise transcriptome analysis based on HA-induced stress tolerance has not been identified.

Here we elucidate the transcriptome changes due to HA application under salt stress conditions to understand how HA confers salt stress tolerance in transcriptional levels. Under salt stress conditions, HA up-regulates genes involved in response to stimuli, such as genes encoding HSPs and GLUTAREDOXINs (GRXs/ROXYs) and downregulates genes involved in response to biotic stress and metabolic processes. We also identify the transcripts commonly regulated by HA both in the absence and presence of salt stress. These findings suggest that the wide-ranging roles of HA promote agricultural use for a plant growth stimulator and a protective agent helping endure against unfavorable environments.

\section{Results and Discussion}

\subsection{HA Application Confers Salt Stress Yolerance in Arabidopsis and Italian Ryegrass}

We recently reported that HA promotes seed germination, lateral root development, and salt stress tolerance in Arabidopsis [11,14]. Here we reevaluated the HA-induced salt stress tolerance at the germination stage of Arabidopsis, unlike previous salt stress response monitored at the seedling stage. Arabidopsis (Columbia ecotype background) wild-type seeds were germinated in Murashige and Skoog (MS) media or MS containing $860 \mathrm{mg} \mathrm{L}^{-1}$ HA supplemented with or without $100 \mathrm{mM} \mathrm{NaCl}$. Seed germination and consequent early seedling development were suppressed by salinity stress, as previously reported [15], but its inhibition was partly rescued by HA application (Figure 1a). Relative fresh weight and chlorophyll content (in the presence vs. absence of $100 \mathrm{mM} \mathrm{NaCl}$ ) were significantly higher in HA applied plants (Figure $1 b, c)$. Thus, these data and our previous finding suggest that HA helps escape salt-induced inhibition of seed germination as well as that of seedling development in Arabidopsis.

To extend the agricultural application of HA, we examined HA-induced salt tolerance in Italian ryegrass, a high-quality forage crop widely cultivated in temperate regions. We previously found that HA promotes seedling growth and regrowth after cutting of Italian ryegrass by foliar application [16]. Ten-d old Italian ryegrass seedlings were exposed to salt stress by submerging in $250 \mathrm{mM} \mathrm{NaCl}$ solution, and $\mathrm{HA}\left(860 \mathrm{mg} \mathrm{L}^{-1}\right)$ or water (as a control) applied directly by foliar spraying at 0,3 , and 6 days after salt treatments. Under $250 \mathrm{mM} \mathrm{NaCl}$ treatments for $10 \mathrm{~d}$, HA-sprayed seedlings were extremely tolerant compared to water-sprayed seedlings (Figure 1d). Fresh weight and chlorophyll content were significantly higher in HA-treated Italian ryegrass seedlings compared to watertreated seedlings (Figure 1e,f). Interestingly, these results indicate that foliar application of HA helps plants overcome the soil-born salt stress through an unknown pathway and, in addition, bioactivity of HA including salt stress tolerance is not limited to Arabidopsis, a model plant. HA thus stimulates defense systems of various plants under salt stress. 
a

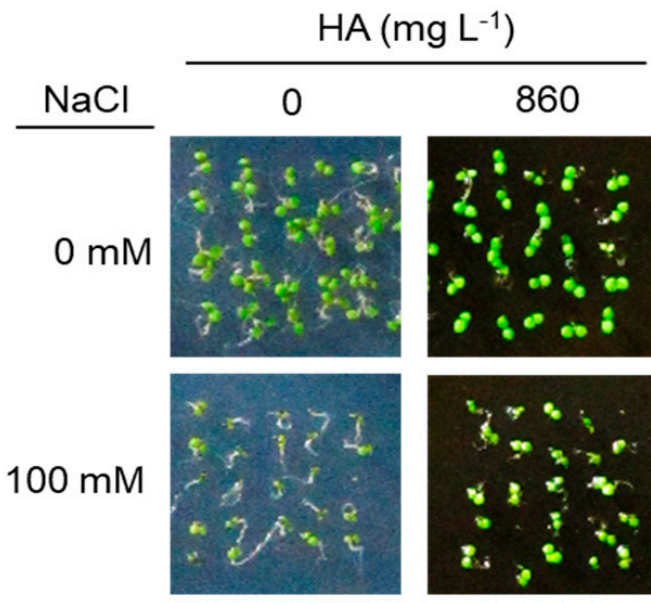

d

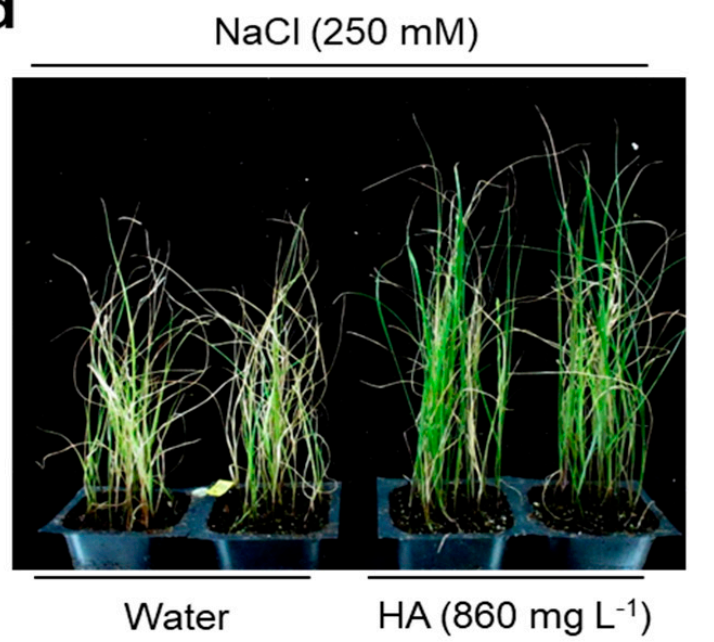

b

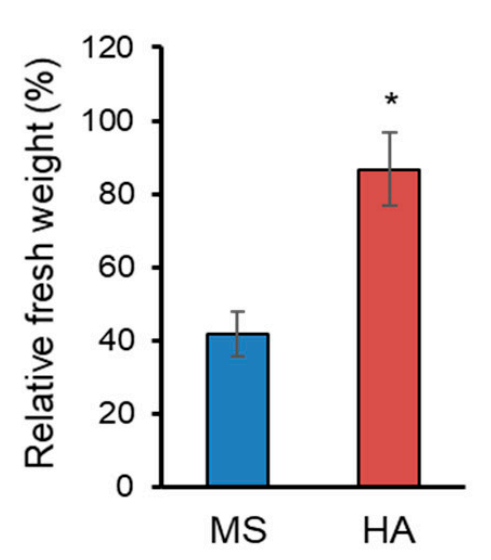

e

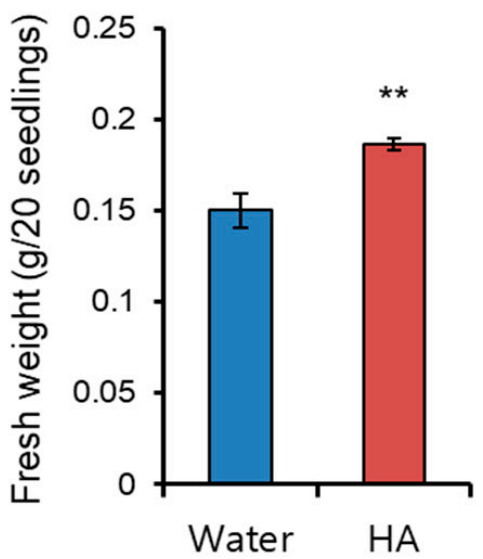

C

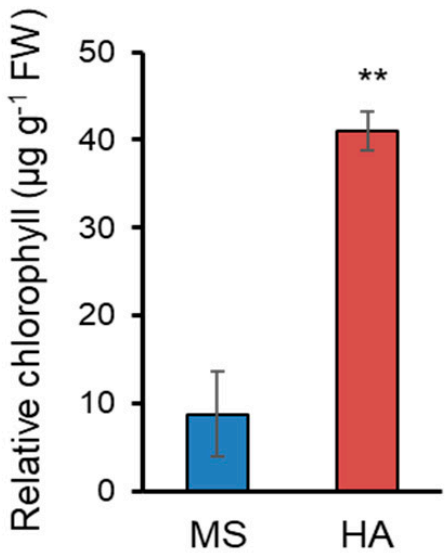

f

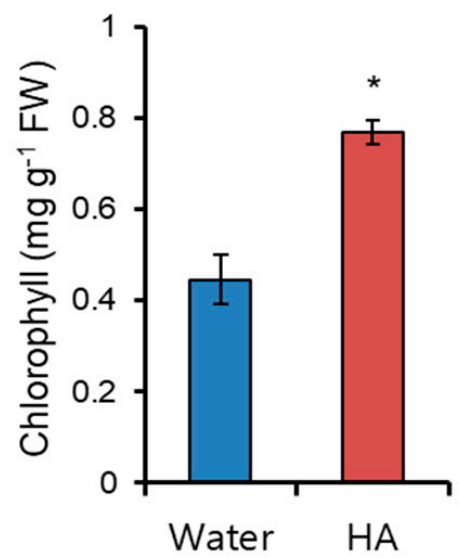

Figure 1. Humic acid (HA) confers salt stress tolerance in Arabidopsis and Italian ryegrass. (a-c) HA-induced salt stress tolerance in Arabidopsis. (a) Pictures shown 7-d-old wild-type Arabidopsis (Col-0) seedlings grown in 1/2 Murashige and Skoog (MS) media or that containing $860 \mathrm{mg} \mathrm{L}^{-1} \mathrm{HA}$ supplemented with or without $100 \mathrm{mM} \mathrm{NaCl}$ for $7 \mathrm{~d}$. (b) Relative fresh weight and (c) relative chlorophyll content (in the presence vs. absence of $100 \mathrm{mM} \mathrm{NaCl}$ ). Fresh weight and chlorophyll contents were measured and relatively calculated (salt-treated values divided by non-treated). Data represent means $\pm \mathrm{SE}$, $n=3 .{ }^{*} p<0.05,{ }^{* *} p<0.01$ compared with seedlings grown in MS media. (d-f) HA-induced salt tolerance in Italian ryegrass. (d) Picture shown 20-d old Italian ryegrass seedlings exposed to $250 \mathrm{mM} \mathrm{NaCl}$ for $10 \mathrm{~d}$ with foliar application of water or HA (860 mg L ${ }^{-1}$ ) by spray. (e) Fresh weight and (f) chlorophyll contents were measured. Data represent means $\pm \mathrm{SE}, n=3$. ${ }^{*} p<0.05,{ }^{* *} p<0.01$ compared with seedlings sprayed with water.

\subsection{Illumina Sequencing, Mapping Sequence Reads, and Total Differentially Expressed Genes (DEGs)}

HSs positively affect both soil properties and plants, and HA is suggested to modulate biochemical and molecular processes involving nutrient uptake, lateral root development, stomatal response, and salt tolerance at both the transcriptional and post-transcriptional level [17-20]. In a previous study, we reported the transcriptome changes by HA application in Arabidopsis, and found that $21 \%$ of 416 differentially expressed genes (DEGs) upregulated by HA enriched in the "response to stimulus" Gene Ontology (GO) category to " biological processes" (GO:0008150) [12]. To elucidate the molecular evidence of HAinduced salt stress tolerance, we performed transcriptome analysis using Arabidopsis seedlings exposed to salt $(100 \mathrm{mM} \mathrm{NaCl})$ or salt $+\mathrm{HA}\left(860 \mathrm{mg} \mathrm{L}^{-1}\right)$ treatment for $9 \mathrm{~h}$ with previous HA-treated samples [12]. 
We sequenced cDNA libraries constructed for each treatment using the Illumina HiSeq 2500 platform. A total of 632,280,782 sequence reads were produced from all four treatments (MS as a control, HA, salt, and salt + HA) including treatments in a previous report (MS or HA treatment [12]) with three replications. On average, $94 \%$ of the quality-filtered reads were generated for all samples uniquely mapped to the reference genome. The other reads were either $4 \%$ unmapped or did not show primary hits (2\%). A summary of mapping statistics obtained for each treatment is described in Supplementary Table S1.

Transcriptome changes in Arabidopsis seedlings subjected to four treatments were analyzed, and the total transcriptome from each treatment was compared to identify the DEGs among pairs of treatments. From comparisons between MS and salt (DEG \#1), MS and HA (DEG \#2), salt and salt + HA (DEG \#3), and HA and salt + HA (DEG \#4), a total of $3785,3257,5271$, and 2582 DEGs were isolated, respectively (Supplementary Figure S1). In a previous report, we identified DEG \#2, mainly regulated by HA, and found that HA triggers transcriptional activation of genes encoding HEAT-SHOCK PROTEINs (HSPs) and consequently confers heat stress tolerance in Arabidopsis [12]. Thus, in this study, we focused on the transcriptional changes in DEG \#3 to elucidate the molecular mechanisms of HA conferring salt stress tolerance in Arabidopsis.

\subsection{Up-Regulated Genes by HA under Salt Stress (DEG \#3)}

Of 5271 DEGs ( $\log _{2}$ fold change $\geq 0.3$ and cutoff $q$-value $\left.<0.05\right)$ in DEG \#3, 2483 genes were significantly up-regulated by HA, while 2788 genes were significantly down-regulated by HA (Supplementary Figure S1 and Additional file 1). As described for DEG \#2 [12], we reanalyzed DEGs showing a $\log _{2}$ fold change $\geq 1$ and $\leq-1$ for up- and down-regulated genes, respectively. Under salt stress conditions, a total of 515 genes were up-regulated by HA application, while 620 genes were down-regulated by HA. GO term enrichment analysis [21] was performed for the 515 up-regulated genes in DEG \#3, and the 50 most up-regulated genes in DEG \#3 are shown in Supplementary Figure S2a. Among the 515 genes, 22\% of DEGs were significantly enriched (False Discovery Rate, FDR $=1.5 \times 10^{-6}$ ) in the "response to stimulus" (GO:0050896) GO category (Figure 2a and Supplementary Figure S3). Among these, 34 genes were associated with the "response to abiotic stimulus" (GO:00009628, FDR $\left.=1.8 \times 10^{-5}\right), 41$ genes associated with the "response to stress" (GO:0006950, FDR $=0.00038$ ), and 33 genes associated with "response to chemical stimulus" (GO:0042221, $\mathrm{FDR}=0.012$ ) (Figure 2b).

\subsubsection{Up-regulated Genes Involved in Response to Light Stimulus}

Genes associated with the "response to light stimulus" were PHYTOCHROME KINASE SUBSTRATE 4 (PKS4, AT5G04190), FAR-RED-ELONGATED HYPOCOTYL1-LIKE (FHL, AT5G02200), LONG HYPOCOTYL IN FAR-RED (HFR1, AT1G02340), INDOLE-3ACETIC ACID INDUCIBLE 29 (IAA29, AT4G32280), LIGHT-HARVESTING CHLOROPHYLL A/B-BINDING 2.3 (LHCB2.3, AT3G07500), ARABIDOPSIS THALIANA HOMEOBOX PROTEIN 16 (ATHB16, AT4G40060), and GLUTAMATE SYNTHASE 1 (GLU1, AT5G04140). Red light receptor phytochromes (phy) regulate plant growth including seed germination and hypocotyl elongation [22]. FAR-RED ELONGATED HYPOCOTYL (FHY) and FHL transmit the phyA signal to their downstream transcription factors (TFs) HFR1 and LONG AFTER FAR-RED LIGHT 1 (LAF1), inhibiting hypocotyl elongation [23]. FHY and FAR1 up-regulated by ABA and abiotic stresses, acting as positive regulators of ABA and integrators of light and ABA signaling [24]. One of the four PKS proteins in Arabidopsis, PKS4, negatively regulates phyA/B-mediated hypocotyl growth inhibition and is involved in phototropism [25]. GLU1 is a FERREDOXIN-DEPENDENT GLUTAMINE OXOGLUTARATE AMINOTRANSFERASE 1 (Fd-GOGAT1) catalyzing the synthesis of glutamate from glutamine and $\alpha$-ketoglutarate, and is involved in growth and development [26]. LHCB proteins are the most abundant chloroplast proteins in plants and mainly function in collecting and transferring light energy to photosynthetic reaction centers, positively affecting plant development as well as stress tolerance [27]. Auxin-inducible $I A A$ genes 
promote plant development, and IAA29 is activated by PHYTOCHROME-INTERACTING FACTOR 4 (PIF4) binding to control morphological acclimation to warm temperature [28]. Salt stress causes numerous harmful effects, such as toxic ROS induction and photoinhibition, resulting in the retardation of plant growth [29]. In the presence of salt stress, HA may help to maintain light absorption, light-harvesting capacity, and light-induced plant growth, and subsequently enhance plant survivability.
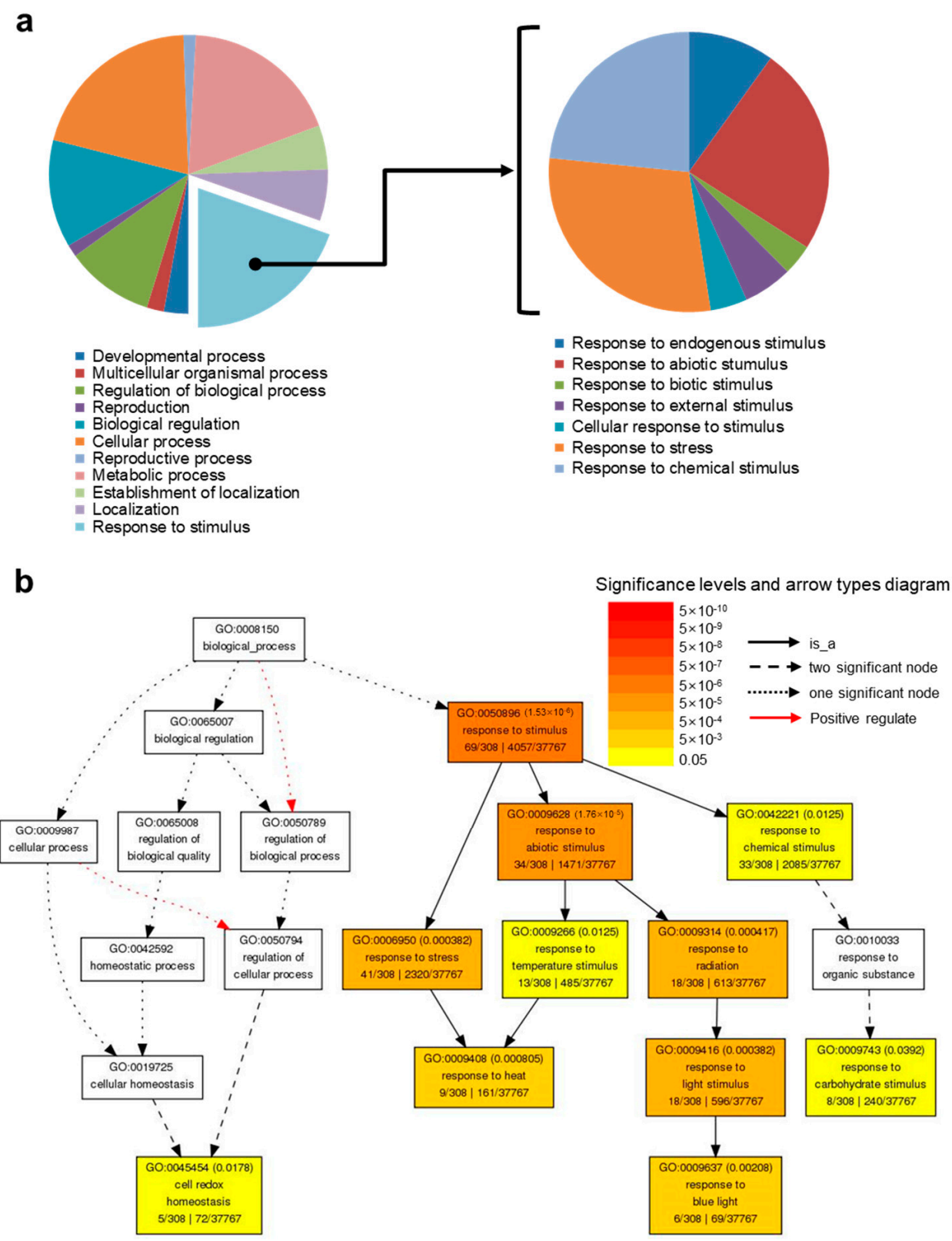

Figure 2. Gene Ontology (GO) enrichment analysis of up-regulated genes in differentially expressed genes (DEG) \#3 (salt vs. salt + HA). (a) GO functional classification. "Biological processes" significantly enriched for up-regulated genes in DEG \#3 (left) and sub-classification of DEGs involved in the response to stimulus (right). (b) GO term enrichment analysis for up-regulated genes in DEG \#3. Each box indicates the GO term and description with the false discovery adjusted (FDR)-adjusted $p$-value; the color scale reflects these adjusted $p$-values. The fraction on the left side at the bottom is the number of genes in our dataset falling into that GO category out of the total number of genes in the list. Boxes with GO terms are presented hierarchically, with the root term at the top and child terms toward the bottom. 


\subsubsection{Up-Regulated Genes Involved in Response to Heat}

Genes enriched in the "response to heat" (GO:0009408, FDR $=0.0008)$ GO term were also associated with GO terms "response to temperature stimulus" (GO:0009266) and "response to stress" (GO:0006950) (Figure 2b). HSP101 (AT1G74310), cytosolic HSP81.1 (AT5G52640), CLASS I SMALL HSP17.6 (AT1G53540), CLASS II SMALL HSP17.6 (AT5G12020), SMALL HSP 17.6A (AT5G12030), MITOCHONDRION-LOCALIZED SMALL HSP23.6 (HSP23.6-MITO, AT4G25200), HS TRANSCRIPTION FACTOR A3 (HSFA3, AT5G03720), TEMPERATURE-INDUCED LIPOCALIN (TIL, AT5G58070), and RESPIRATORY BURST OXIDASE HOMOLOG B (ATRBOHB, AT1G09090) up-regulated by HA in DEG \#3. Small HSPs with a monomer size of 10-40 kDa form large oligomers and function as molecular chaperones to prevent thermal denaturation of substrates [30]. The transcripts of small HSPs are rapidly induced by stress, and plants overexpressing small HSPs exhibit not only heat tolerance but also tolerance to diverse abiotic stresses via increased chaperoning capacity resulting in protein homeostasis [31,32]. The HSFA3 transcription factor activates many heat-inducible genes, and its overexpression enhances thermotolerance [33]. TIL is involved in heat and salt stress tolerance, probably by preventing membrane lipid peroxidation caused by heat stress and inhibiting chloroplast destruction caused by ion toxicity, respectively [34,35]. $R B O H B$ encodes an NADPH oxidase generating $\mathrm{H}_{2} \mathrm{O}_{2}$ and is specifically expressed in roots; the increased superoxide confers salt stress tolerance in grafted cucumber by promoting $\mathrm{Na}^{+}$exclusion from roots and early stomatal closure $[8,36]$. Thus, HA may protect salt-induced intracellular protein damage via the transcriptional activation of HSPs and RBOHB.

\subsubsection{Up-Regulated Genes Involved in Response to Cell Redox Homeostasis}

In addition, up-regulated genes involved in cell redox homeostasis (GO:0045454, FDR $=0.0178$ ) were significantly enriched in DEG \#3 (Figure $2 b$ ). These genes encode class III (CC-type) GRXs/ROXYs (AT3G62930, ROXY16; AT4G15680, ROXY13; AT1G15690, ROXY12; AT4G15700, ROXY11; AT5G18600, ROXY10), acting as glutathione-dependent disulfide oxidoreductases involved in oxidative stress responses [37]. ROXY genes are differentially regulated by nitrate; 6 ROXYs (ROXY6, 8, 9, 19-21) are up-regulated and 10 ROXYs (ROXY7, 10-18) are down-regulated under nitrate deprivation, while 7 ROXYs (ROXY4, 11-13, 15-17) are up-regulated by the addition of nitrate [38,39]. A gain-offunction study using ROXY15 suggests a positive and negative involvement in chlorophyll content and root hair elongation, respectively [39]. Thus, HA helps plants escape saltinduced toxicity through induction of ROXY genes to maintain cellular redox homeostasis, which subsequently drive physiological outputs such as proper functioning of chlorophyll and normal root development under salt stress conditions.

\subsection{Down-Regulated Genes by HA under Salt Stress (DEG \#3)}

GO term enrichment analysis [21] of 620 genes down-regulated by HA in DEG \#3 revealed that $65 \%$ of these DEGs $(409 / 620)$ were associated with the "biological process" category (GO:0008150) and significantly enriched (FDR < 0.05) in the "regulation of biological process" (GO:0050789), "multi-organism process"(GO:0051704), and "response to stimulus" (GO:0050896) GO categories (Supplementary Figure S4 and Additional file 1). The 50 most down-regulated genes in DEG \#3 are shown in Supplemental Figure S2b. The GO categories of down-regulated genes in DEG \#3 were biotic stress-related ("response to biotic stimulus", GO:0009607; "defense response", GO:0006952; "response to wounding", GO:0009611) and primary and secondary metabolic process-related ("pigment metabolic process", GO:0042440; "secondary metabolic process", GO:0019748; "phenylpropanoid metabolic process", GO:0009698) GO terms (Figure 3). 

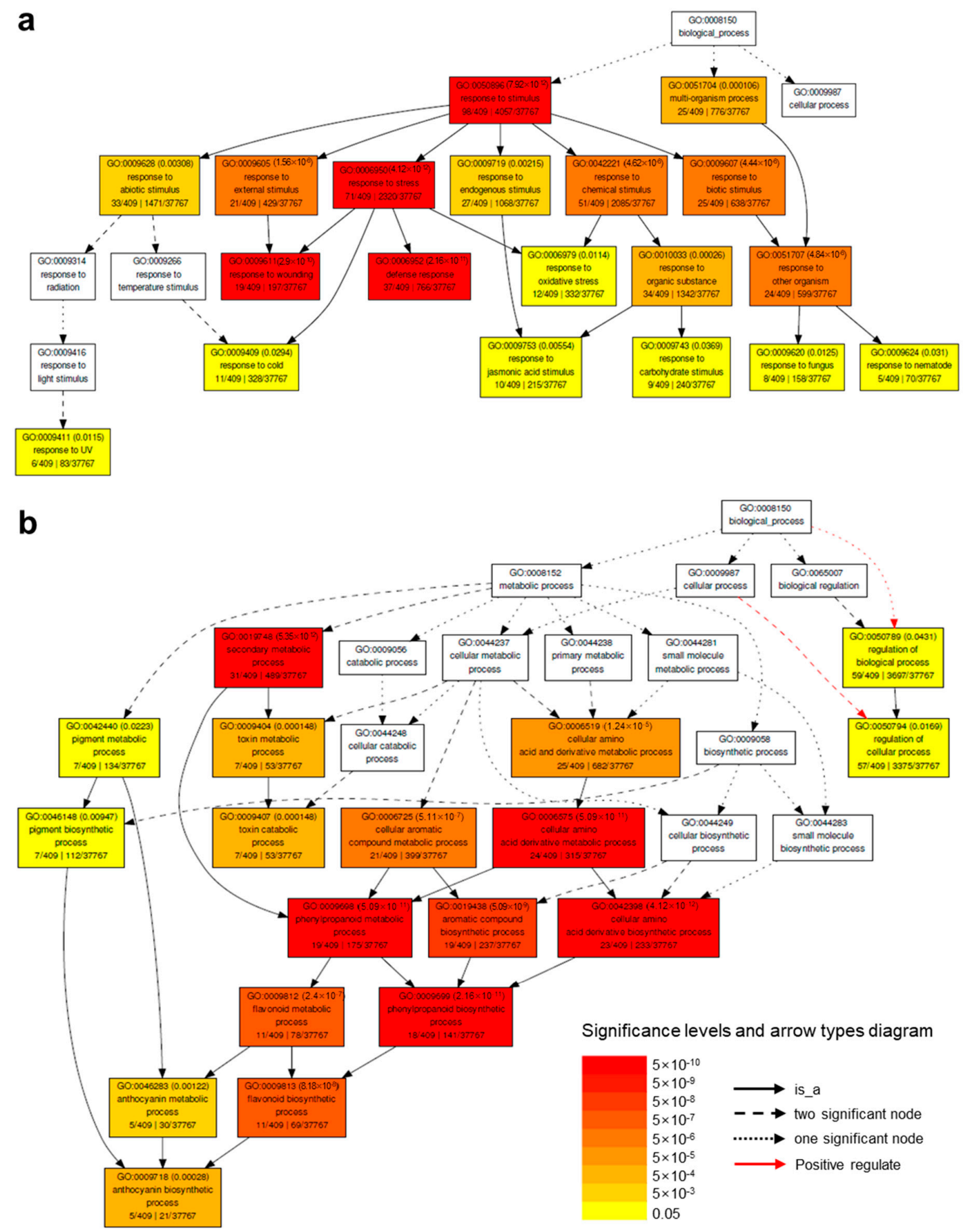

Figure 3. GO enrichment analysis of down-regulated genes in DEG \#3 (salt vs. salt + HA). GO term enrichment analysis for down-regulated genes in DEG \#3 enriched in the response to stimulus (a) and metabolic process (b) GO categories. Representations are described in the Figure $3 \mathrm{~b}$ legend.

\subsubsection{Down-Regulated Genes Involved in Toxin Catabolic Process}

Down-regulated genes involved in the "toxin catabolic process" (GO:0009407, FDR < 0.001) were mainly plant-specific phi- (GLUTATHIONE S-TRASNSFERASE F, GSTF) and tau- (GSTU) type GST genes (GSTs; ATGSTU3, AT2G29470; ATGSTU6, AT2G29440; ATGSTU11, AT1G69930; ATGSTU12, AT1G69920; ATGSTF6, AT1G02930; ATGSTF12, AT5G17220). GST catalyzes S-conjugation between the thiol group of reduced glutathione and toxic substrates to reduce cellular toxicity [40]. The expression patterns of GSTs belonging to multi-gene families are differentially regulated by external conditions such as 
a/biotic stresses and internal factors such as ROS and phytohormones, and their downregulation by HA under salinity stress might be related to the down-regulation of genes associated with biotic stress-related GO terms [41,42].

\subsubsection{Down-Regulated Genes Involved in the Metabolic Process}

Genes down-regulated by HA in the "metabolic process" category were significantly enriched in the "pigment metabolic process" (GO:0042440, FDR = 0.0011) and "secondary metabolic process" (GO:0019748, FDR $=6.7 \times 10^{-12}$ ) GO categories (Figure 3b). Genes in the "pigment metabolic process" category were mainly associated with anthocyanin biosynthesis GO terms ("proanthocyanidin biosynthetic process", GO:0010023; "regulation of anthocyanin biosynthetic process", GO:0031540; "anthocyanin biosynthetic process", GO:0009718), such as ANTHOCYANIDIN SYNTHASE (ANS, AT4G22880), PRODUCTION OF ANTHOCYANIN PIGMENT 1 (PAP1, AT1G56650), and TRANSPARENT TESTA 5 (TT5, AT3G55120). Anthocyanins are water-soluble plant pigments of the flavonoid sub-class of phenylpropanoids and are induced by diverse environmental stress responses [43]. In addition, genes enriched in the "secondary metabolic process" GO term mainly belonged to the "phenylpropanoid metabolic process" (GO:0009698, FDR $=2.2 \times 10^{-12}$ ) and were sub-classified into the "flavonoid metabolic process" (GO:0009812, FDR $=8.7 \times 10^{-10}$ ) and "phenylpropanoid biosynthetic process" (GO:0009699, FDR $=3.5 \times 10^{-10}$ ) GO categories. Most anthocyanin-related genes were also associated with both these sub-categories of the "secondary metabolic process" GO term. Flavonoids and phenylpropanoids are secondary metabolites produced in plants, especially for protecting against biotic stress, although they are also involved in abiotic stress responses [44].

\subsection{Validation of DEGs by Quantitative RT-PCR ( $q R T-P C R$ )}

Transcriptome data were validated by qRT-PCR. Transcripts of three ROXYs including ROXY10, 12, and 13 were enhanced by HA in the presence of salt stress (Figure $4 a-c$ ). Two HSP genes such as HSP101 and HSP81.1 increased by salinity stress compared with MS, and furthermore those expressions were stimulated by HA applications in the presence of salt treatment (Figure 4d,e). Interestingly, HSP genes up-regulated by HA both in the absence and presence of salt stress [12], suggesting that HSP genes are major molecular targets of HA facilitating proteostasis. In addition, anthocyanine-involved gene TRANSPARANT TESTA 5 (TT5, AT3G55120) rapidly decreased by HA in the presence of salt stress (Figure 4f). These qRT-PCR data are consistent with transcriptome analysis.
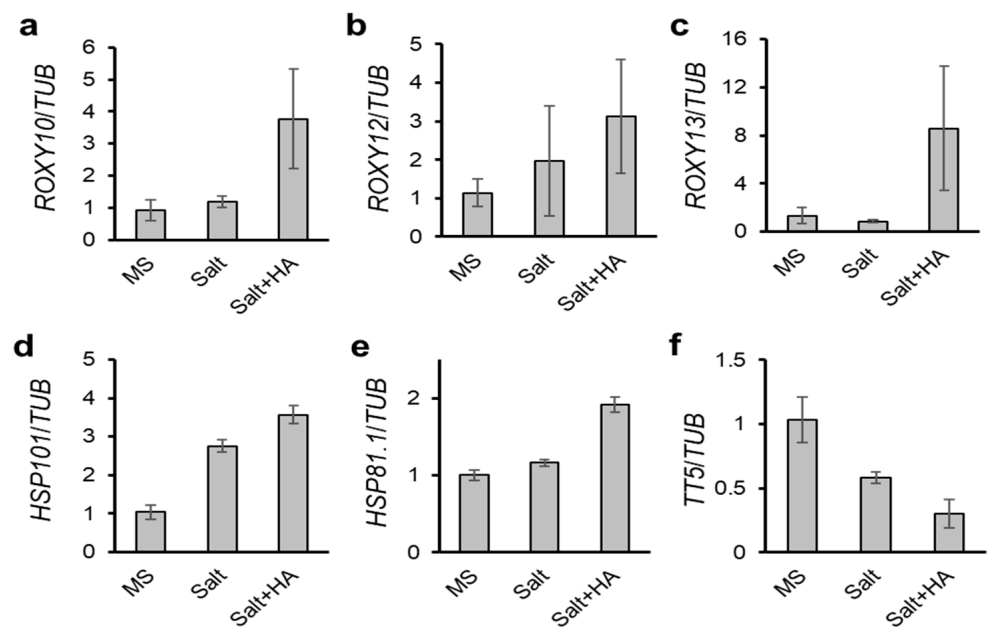

Figure 4. Validation of DEGs by qRT-PCR. One-week old Arabdopsis wild-type seedlings were treated with HA $\left(860 \mathrm{mg} \mathrm{L}^{-1}\right)$, salt $(100 \mathrm{mM} \mathrm{NaCl})$, or salt + HA for $9 \mathrm{~h}$. Transcripts of ROXY10 (a), ROXY12 (b), ROXY13 (c), HSP101 (d), HSP81.1 (e), and TT5 (f) were validated by qRT-PCR and normalized to that of TUB. Data represent means $\pm S E, n=3$. 
2.6. Transcripts Regulated in Common between DEG\#2 (MS vs. HA) and DEG \#3 (Salt vs. Salt $+H A)$

Identification of transcripts commonly expressed between DEG \#2 and DEG \#3 will help understand the unknown function of HA at the transcriptional level in either the absence or presence of salt stress. Up- and down-regulated DEGs showing $\log _{2}$ fold change $\geq 1$ and $\leq-1$, respectively, were compared, and 269 genes were commonly up-regulated while 188 genes were down-regulated by HA in both DEG \#2 and DEG \#3 (Figure 5 and Additional file 2). We first analyzed the 269 up-regulated genes using GO analysis, and $20 \%$ of genes associated with the "biological process" (GO:0008150) category were significantly enriched in the "response to stimulus" (GO:0050896, FDR < 0.05) GO category (Supplementary Figure S5). Various stress-related genes including those associated with ozone (AT1G01170), osmotic (ALCOHOL DEHYDROGENASE 1 (ADH1), AT1G77120), heat (HSP17.6A, HSP23.6-MITO, and HSP81.1), and universal stress (UNIVERSAL STRESS PROTEIN (USP) FAMILY PROTEINs, AT3G03270 and AT3G62550) responses were upregulated in both DEG sets.

\section{UP}

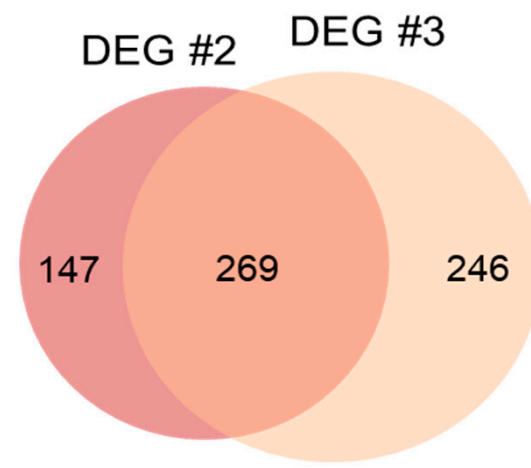

DOWN

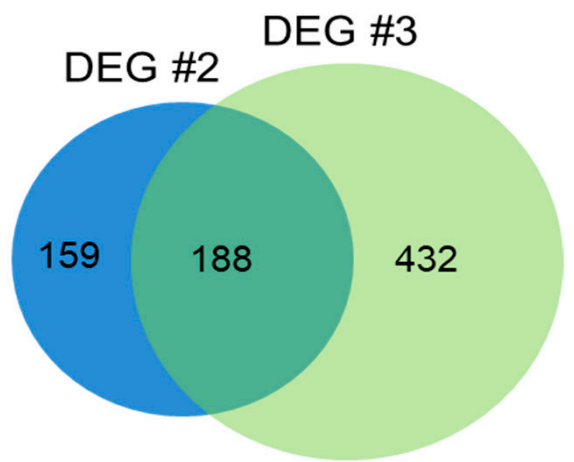

Figure 5. Venn diagram representing up- or down-regulated DEGs common to DEG \#2 and DEG \#3. The numbers represent significantly up- (left) and down- (right) regulated genes by HA in DEG \#2 and DEG \#3, indicating those regulated in common between DEG \#2 and DEG \#3.

In addition, genes involved in the response to oxidative stress (GO:0006979, FDR < 0.05) were significantly enriched: SENESCENCE 1 (SEN1, AT4G35770), HSP17.6A, OXIDATIVE STRESS 3 (OXS3, AT5G56550), ARABIDOPSIS ORTHOLOG OF SUGAR BEET HS1 PRO-1 2 (HSPRO2, AT2G40000), and three unknown genes (AT3G10020, AT5G59080, and AT1G73120). Senescence-associated gene SEN1 was increased by the ROS inducer methyl viologen [45]. OXS3 confers tolerance to heavy metals and oxidative stress, possibly as a chromatic remodeling factor [46]. Heat stress-induced ROS trigger the induction of HSP genes, including HSP17.6A [47].

Approximately $30 \%$ of all genes encode proteins with currently unknown functions, and genetic transformation has been challenged by identifying the functional roles of these genes. Plants overexpressing AT1G01170 are tolerant to salt stress, while those overexpressing AT5G59080 and AT1G73120 show enhanced tolerance to T-butyl hydroperoxide and paraquat-induced oxidative stress $[48,49]$. USP genes belong to a large gene family that responds to diverse environmental stresses; USP proteins act as redox-dependent and RNA chaperones, subsequently enhancing heat, cold, and oxidative stress tolerance [50,51]. ADH1 expression is induced substantially by diverse stresses, and plants overexpressing ADH1 show enhanced stress tolerance to salt, drought, cold, and pathogen infection [52]. The analysis of commonly up-regulated genes showed that HA triggers the expression of a variety of genes involved in stress resistance both in the absence and presence of salt stress, conferring a protective effect on plants prior to exposure of stress. 
Among 188 genes down-regulated by HA in both DEG \#2 and DEG \#3, genes associated with the "metabolic process" (GO:0008152) GO term were significantly enriched in the "pigment metabolic process" (GO:0042440, FDR $=1 \times 10^{-5}$ ), "secondary metabolic process" (GO:0019748, FDR $=4 \times 10^{-13}$ ), and "biosynthetic process" (GO:0009058, FDR = 0.0067) GO sub-categories (Figure 5 and Supplementary Figure S6). The phenylpropanoid-related biosynthetic genes for flavonoids and anthocyanins, PRODUCTION OF ANTHOCYANIN PIGMENT 1 (PAP1, AT1G56650), RIBONUCLEASE 1 (RNS1, AT2G02990), UDPGLUCORONOSYL/UDP-GLUCOSYL TRANSFERASE (UGT89C1, AT1G06000), TT5, and FLAVONOL SYNTHASE 1 (FLS1, AT5G08640), were down-regulated in both the absence and presence of salt stress. The flavonoid biosynthetic genes determine the testa color, and encoded proteins are involved in various steps for the synthesis of flavonoids and anthocyanidins [53,54]. In transcriptome coexpression analysis in Arabidopsis, UGT89C1 is highly correlated with known flavonoid biosynthetic genes [55]. In addition, genes associated with wounding stress and defense response were down-regulated by HA in both DEG sets: RECEPTOR LIKE PROTEIN 6 (AtRLP6, AT1G45616), AtRLP23 (AT2G32680), AtRLP33 (AT3G05560), THIONIN/PATHOGENESIS-RELATED-13 (PR-13, AT1G66100), LIPOXYGENASE 3 (LOX3, AT1G17420), and DIRIGENT (DIR)-LIKE PROTEIN (AT4G11190). RLPs sensing extracellular signals are transmembrane receptors with extracellular leucinerich repeat domains, and they play an important role in disease resistance by recruiting RECEPTOR-LIKE KINASE proteins to activate downstream signals [56]. The 13Lipoxygenase (13-LOX) protein encoded by LOX3 induces oxylipin biosynthesis, which is triggered by the recognition of the avirulent protein Avr-Rpm1 [57]. DIRs and DIR-like protein dictate the stereoselectivity of phenoxy radical coupling during lignin biosynthesis and are transcriptionally induced and spatially targeted during the response to pathogen infection $[58,59]$. Upon the down-regulation of these positive regulators to biotic stress by HA, HA may negatively modulate the biotic stress response of plants.

\subsection{Transcription Factors Regulated in Common between DEG \#2 (MS vs. HA) and DEG \#3 (Salt} vs. Salt $+H A)$

TFs regulate gene expression in diverse plant development as well as stress responses, and the Arabidopsis genome contains around 2000 TF genes [60]. In total, 27 TF genes were up-regulated by HA in DEG \#2 while 44 TF genes up-regulated in DEG \#3 (Figure 6a-c and Additional file 2). From this, we analyzed the TF genes regulated in common between DEG \#2 and DEG \#3, and 14 TF genes encoding a bZIP TF (bZIP63/BZO2H3, AT5G28770), CCCH zinc finger TFs (AtTZF/ZFP1 (AT2G25900) and TZF5 (AT5G44260)), Bbox type zinc finger TF (BBX17, AT1G49130), ETHYLENE RESPONSE FACTOR (ERF) type TF (HYPOXIA RESPONSIVE ERF 2 (HRE2/ERF71), AT2G47520), ERF TF (AT3G60490), homeodomain-like TF (BROTHER OF LUX ARRHYTHMO (BOA), AT5G59570), GATA type TF (GATA TF 4 (GATA4), AT3G60530), GRAS family TF (AT3G46600), LATERAL ORGAN BOUNDARIES (LOB) DOMAIN-CONTAINING PROTEIN 40 (LBD40, AT1G67100), MADS-box TF (AGAMOUS-LIKE 44 (AGL44), AT2G14210), Myb-like TF (REVEILLE 1 (RVE1), AT5G17300), NUCLEAR FACTOR Y subunit C4 (NF-YC4, AT5G63470), and sequence-specific DNA binding TF (HYPOXIA RESPONSE ATTENUATOR 1 (HRA1), AT3G10040) were commonly up-regulated. AtTZF/ZFP1 is up-regulated by salt stress, and plants overexpressing AtTZF/ZFP1 show enhanced salt stress tolerance by maintaining ionic balance through negative regulation of oxidative and osmotic stresses [61]. TZF5 interacts with the stress-responsive protein $\mathrm{RD} 21 \mathrm{~A}$, regulating stress responses [62]. The AP2/ERF family TF gene HRE2/ERF71 is highly responsive to diverse abiotic stresses, such as anoxia, $\mathrm{NaCl}$, mannitol, $\mathrm{ABA}$, and methyl viologen, and transgenic plants overexpressing HRE2/ERF71 are tolerant to stress conditions [63]. The GARP family TF BOA is regulated by the circadian clock, and overexpression of BOA triggers physiological and developmental changes such as increased vegetative growth [64]. GATA4 is involved in the positive regulation of primary and lateral root development [65]. LOB domain-containing genes have 40 homologs with functional redundancy in Arabidopsis producing morphological changes in lateral organ development; LBD40 is mainly expressed in roots [66]. 
The MADS-box TF AGL44 causes nitrogen-mediated morphological changes including rapid early seedling development, increased root capacity, and increased fresh weight of shoots [67]. In chlorophyll biosynthesis, protochlorophyllide oxidoreductases (PORs) catalyzes the reduction of protochlorophyllide to chlorophyllide via light stimulation; the TF RVE1 directly binds to PORA promoters, playing a crucial role in chlorophyll biosynthesis by triggering seedling greening during early plant development [27]. Collectively, HA up-regulates various TFs regulating seedling and root development, and abiotic stress tolerance either in the absence or presence of stress.

a

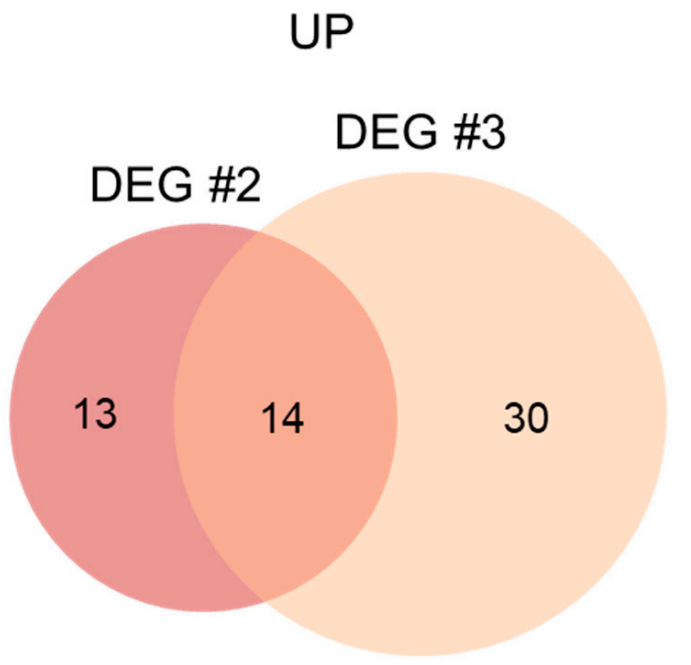

b

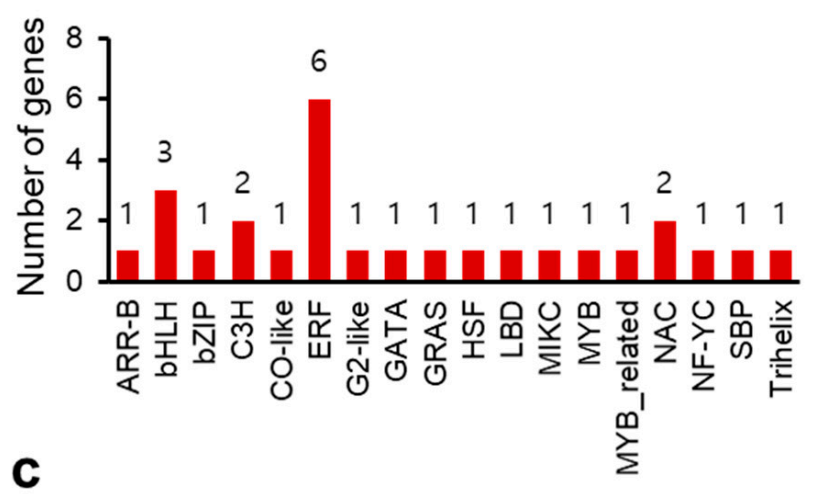

d DOWN

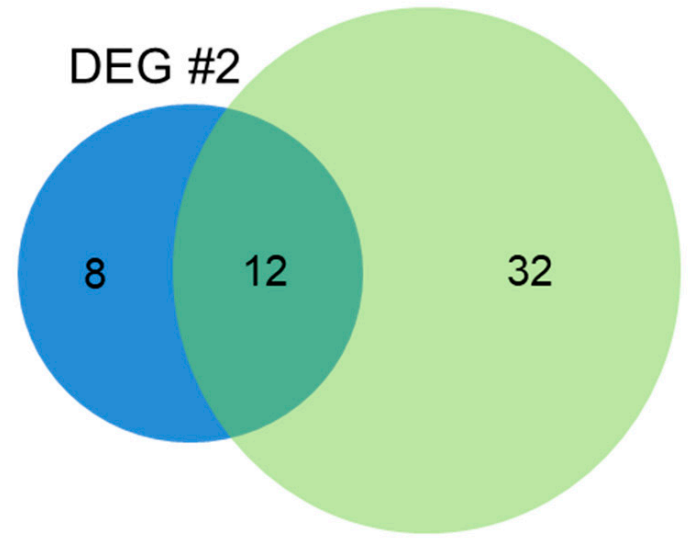

e

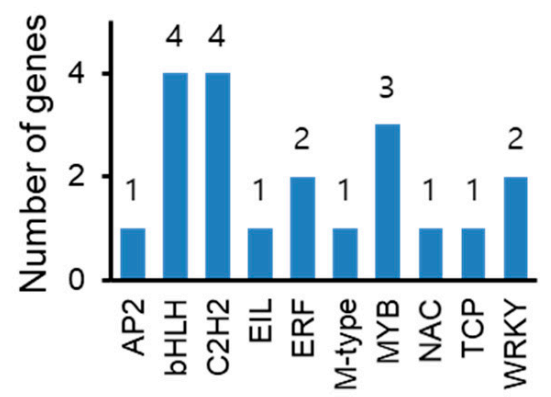

f

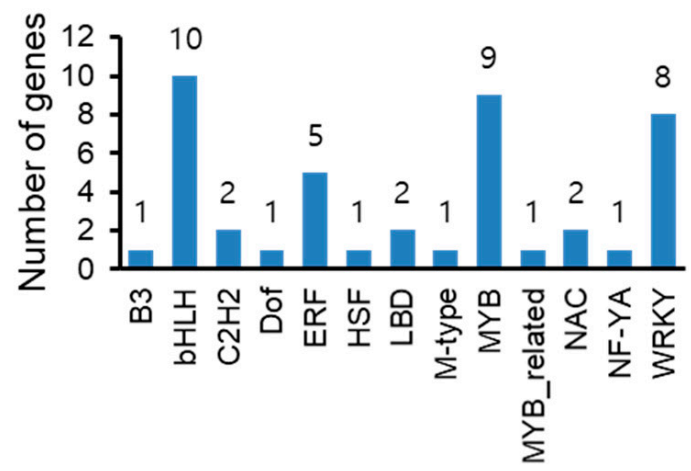

Figure 6. Number of up- or down-regulated transcription factor genes in DEG \#2 and DEG \#3. The number of TF genes significantly up- $\left(\mathbf{a}-\mathbf{c}, \log _{2}\right.$ fold change $\left.\geq 1\right)$ or down- $\left(\mathbf{d}-\mathbf{f}, \log _{2}\right.$ fold change $\left.\leq-1\right)$ regulated in DEG \#2 (d,e) and DEG \#3 $(\mathbf{c}, \mathbf{f})$ represented as a Venn diagram $(\mathbf{a}, \mathbf{d})$ or a bar graph (b,c for up-regulated TF genes; $\mathbf{e}, \mathbf{f}$ for down-regulated TF genes). 
Twenty TF genes were down-regulated by HA in DEG \#2, and 44 TFs in DEG \#3 (Figure 6d-f and Additional file 2). Genes encoding Myb domain-containing TFs PAP1, MYB90 (AT1G66390), and MYB111 (AT5G49330), WRKY TFs WRKY30 (AT5G24110) and WRKY54 (AT2G40750), bHLH TFs MYC67 (AT3G61950) and AT4G20970, and ERF TFs TINY2 (AT5G11590) and CYTOKININ RESPONSE FACTOR 3 (CRF3, AT5G53290), C2H2 zinc finger TF AT5G60470, and MADS-box TF AT5G55690 were down-regulated by HA in both DEG sets (Figure $6 \mathrm{~d}-\mathrm{f}$ ). Anthocyanin biosynthesis is controlled by a ternary TF complex consisting of WD40, bHLH, and Myb (WBM) TFs, such as TRANSPARENT TESTA GLABRA (TTG), GLABRA 3 (GL3), ENHANCER OF GLABRA 3 (EGL3), PAP1, PAP2/MYB90, MYB113, and MYB114 [68]. WRKY30 is involved in leaf senescence and responds to ROS, while WRKY54 participates in the regulatory network to regulate the leaf senescence process with possible cooperation with WRKY30 [69]. CRF5-overexpressing plants display smaller shoot size with reduced rosette leaf size and accelerated leaf senescence compared to wild-type plants but are tolerant to pathogen attack [70,71]. The physiological contributions of these commonly down-regulated TF genes overlap with GO terms of down-regulated DEGs, strongly suggesting that HA reduces the expression of genes involved in phenylpropanoid-related biosynthetic pathways triggering the reduction of anthocyanin and flavonoid accumulation and, furthermore, negatively regulating the expression of genes involved in plant growth.

\section{Materials and Methods}

\subsection{Plant Materials, Growth Conditions and Treatments}

To examine a salt tolerance assay in Arabidopsis, wild-type Arabidopsis (Col-0 ecotype background) seeds were surface-sterilized, prepared on 1/2 MS media (Duchefa Biochemie, Haarlem, the Netherlands) supplemented with or without $860 \mathrm{mg} \mathrm{L}^{-1} \mathrm{HA}$ (Sigma Aldrich (Cat No\#53680), St. Louis, MO, USA) [72], the most appropriate concentration of HA for conferring salt stress tolerance based on our previous report $[11,14]$, in the absence and presence of $100 \mathrm{mM} \mathrm{NaCl}$, and grown for 7 days.

Italian ryegrass (Lolium multiflorum Lam. "Kowinearly"), seeds were kindly provided by the National Institute of Animal Science (Rural Development Administration, Korea). Twenty seeds were directly sown in potting soil No. 2 (Farmhannong, Korea), and germinated in the dark. Ten-day-old seedlings were treated with salt stress by submerging in $250 \mathrm{mM} \mathrm{NaCl}$ solution for 10 days, and water (as a control) or HA (860 $\mathrm{mg} \mathrm{L}^{-1}$ ) sprayed onto the leaves at 0,3 , and 6 days after salt treatments.

For transcriptome and qRT-PCR analyses, surface-sterilized seeds of wild-type Arabidopsis (Col-0) were grown on 1/2 MS media for 7 days, and seedlings were treated with salt $(100 \mathrm{mM} \mathrm{NaCl}), 860 \mathrm{mg} \mathrm{L}^{-1} \mathrm{HA}$, or salt $+\mathrm{HA}$ for $9 \mathrm{~h}$. All plants were grown at $22{ }^{\circ} \mathrm{C}$ under $16 \mathrm{~h}$ light $/ 8 \mathrm{~h}$ dark cycle with $100 \mu \mathrm{mol}$ photons $\mathrm{m}^{-1} \mathrm{~s}^{-1}$.

\subsection{Chlorophyll Content}

Freshly harvested plant samples extracted by $80 \%(v / v)$ acetone with agitation of $120 \mathrm{rpm}$ in the dark for 1.5 days. The chlorophyll content was measured using a Beckman DU-800 UV/Vis spectrophotometer (Beckman Coulter, USA) at light wavelength of 645 and $663 \mathrm{~nm}$ and 80\% acetone as a blank, and calculated as reported previously [73].

\subsection{RNA Extraction, Illumina RNA-Seq and Analysis of RNA-Seq Data}

Total RNA was extracted from triplicate biological replications using an RNeasy Plant Mini Kit (Qiagen, Hilden, Germany) according to the manufacturer's instructions. Preparation of RNA libraries, mRNA purification, cDNA synthesis, cDNA library construction, Illumina sequencing, filtering, mapping, and DEG analysis were carried as described previously [12]. Mapping statistics for quality filtered reads generated for Arabidopsis samples are available in Supplementary Table S1 and a previous report (for DEG \#2). 


\subsection{DEG and GO Analysis}

DEGs were identified based on a $q$-value threshold less than 0.05 for correcting errors caused by multiple testing [74]. GO enrichment analysis with the DEGs based on a $\log _{2}$ fold change $\geq 1$ and $\leq-1$ was performed using agriGO v2.0 [75]. A GO-based trend test was performed through the Fisher's exact test [76] to characterize the genes identified from DEG analysis.

\subsection{Validation by Quantitative Reverse-Transcription PCR ( $q R T-P C R$ )}

Harvested samples as described above were frozen in liquid nitrogen immediately, and Total RNA extraction, cDNA synthesis, and qRT-PCR analysis were carried out as described previously [12]. qRT-PCR conditions were as follows: $95^{\circ} \mathrm{C}$ for $5 \mathrm{~min}$; 40 cycles of $95^{\circ} \mathrm{C}$ for $30 \mathrm{~s} ; 58^{\circ} \mathrm{C}$ for $45 \mathrm{~s}$; and $72{ }^{\circ} \mathrm{C}$ for $45 \mathrm{~s}$; followed by $72{ }^{\circ} \mathrm{C}$ for $5 \mathrm{~min}$. Melting curves were analyzed to confirm that the specific target was amplified. The relative expression levels were calculated using the comparative cycle threshold $(\Delta \Delta \mathrm{Ct})$ method. The expression levels of target genes were normalized to the housekeeping gene, TUBULIN (TUB). Triplicate biological replications were performed. Primer sequences are available in Supplementary Table S2.

\section{Conclusions}

We conducted transcriptome analysis to understand the molecular mechanisms of HA promoting salt stress tolerance in Arabidopsis. Transcripts of genes related to responses to stimuli were significantly enriched, with up-regulation of diverse abiotic stress-related genes encoding HSPs and redox proteins by HA under salt stress conditions. By contrast, genes involved in biotic stress and secondary metabolic pathways, especially anthocyanin and flavonoid, were down-regulated by HA. HA also up-regulated various TFs regulating plant development and abiotic stress tolerance, and down-regulated TF genes involved in pigment metabolism and secondary metabolic processes. We concluded that HA triggers an overall alteration of gene expression involved in plant development and stress responses, and thus plays a role in helping plants tolerate salt stress. These findings provide transcriptome-scale molecular evidence for bioactivity driven by HA under salt stress conditions and will expand the environmental adaptability of HA to field crops.

Supplementary Materials: The following are available online, Table S1: Mapping statistics for quality filtered reads generated for Arabidopsis seedlings, Table S2: Primers used in this study, Figure S1: Number of expressed genes by treatment, Figure S2: Transcript levels of the most differentially regulated genes in DEG \#3, Figure S3: GO term enrichment analysis of up-regulated genes in the main categories biological process, cellular component, and molecular function in DEG \#3, Figure S4: GO term enrichment analysis of down-regulated genes in the main categories biological process, cellular component, and molecular function in DEG \#3, Figure S5: GO term enrichment analysis of genes up-regulated in both DEG \#2 and DEG \#3, Figure S6: GO term enrichment analysis of genes down-regulated in both DEG \#2 and DEG \#3. Additional excel files containing DEG lists are the following: Additional file 1: Transcript data of DEG \#3 (both up- and down-regulated genes), Additional file 2: Transcript data of commonly regulated genes and TF genes in both DEG \#2 and DEG \#3 (both up- and down-regulated genes and TFs).

Author Contributions: Conceptualization, J.-Y.C., J.-R.J. and W.-Y.K.; methodology, J.-Y.C. and S.-H.K.; software, J.-Y.C., S.-H.K. and G.-I.S.; validation, J.-Y.C. and M.G.J.; formal analysis, J.-Y.C. and J.-R.J.; investigation, J.-Y.C., M.G.J., G.-I.S. and S.Y.J.; resources, J.-R.J.; data curation, J.-Y.C. and W.-Y.K.; writing-original draft preparation, J.-Y.C. and S.-H.K.; writing-review and editing, J.-Y.C., G.A., M.G.K., and W.-Y.K.; visualization, J.-Y.C. and G.-I.S.; supervision, J.-Y.C. and W.-Y.K.; project administration, J.-Y.C. and W.-Y.K.; funding acquisition, J.-Y.C. All authors have read and agreed to the published version of the manuscript. 
Funding: This research was funded by the National Research Foundation of Korea (NRF) grant funded by the Korean Government (MOE NRF-2016R1D1A3B03934409 and MSIT 2019R1A2C1011173 to J.-Y.C.).

Institutional Review Board Statement: Not applicable.

Informed Consent Statement: Not applicable.

Data Availability Statement: All data supporting the findings of this study are available in the main text or the Supplementary Materials.

Acknowledgments: The present work was carried out with the support of the National Research Foundation of Korea (NRF) grant funded by the Korean Government (MOE NRF2016R1D1A3B03934409 and MSIT 2019R1A2C1011173 to J.-Y.C.).

Conflicts of Interest: The authors declare no conflict of interest.

Sample Availability: Samples of the compounds are available from the corresponding authors.

\section{References}

1. Orsi, M. Molecular dynamics simulation of humic substances. Chem. Biol. Technol. Agric. 2014, 1, 10. [CrossRef]

2. Keeler, C.; Maciel, G.E. Quantitation in the Solid-State13C NMR Analysis of Soil and Organic Soil Fractions. Anal. Chem. 2003, 75, 2421-2432. [CrossRef] [PubMed]

3. Muscolo, A.; Sidari, M.; Nardi, S. Humic substance: Relationship between structure and activity. Deeper information suggests univocal findings. J. Geochem. Explor. 2013, 129, 57-63. [CrossRef]

4. Nikbakht, A.; Kafi, M.; Babalar, M.; Xia, Y.P.; Luo, A.; Etemadi, N.-A. Effect of Humic Acid on Plant Growth, Nutrient Uptake, and Postharvest Life of Gerbera. J. Plant Nutr. 2008, 31, 2155-2167. [CrossRef]

5. Trevisan, S.; Francioso, O.; Quaggiotti, S.; Nardi, S. Humic substances biological activity at the plant-soil interface. Plant Signal. Behav. 2010, 5, 635-643. [CrossRef]

6. Kulikova, N.A.; Abroskin, D.P.; Badun, G.A.; Chernysheva, M.G.; Korobkov, V.I.; Beer, A.S.; Tsvetkova, E.A.; Senik, S.V.; Klein, O.I.; Perminova, I.V. Label Distribution in Tissues of Wheat Seedlings Cultivated with Tritium-Labeled Leonardite Humic Acid. Sci. Rep. 2016, 6, 28869. [CrossRef]

7. Shrivastava, P.; Kumar, R. Soil salinity: A serious environmental issue and plant growth promoting bacteria as one of the tools for its alleviation. Saudi J. Biol. Sci. 2015, 22, 123-131. [CrossRef]

8. Cheong, M.S.; Yun, D.-J. Salt-stress signaling. J. Plant Biol. 2007, 50, 148-155. [CrossRef]

9. Yang, Y.; Guo, Y. Unraveling salt stress signaling in plants. J. Integr. Plant Biol. 2018, 60, 796-804. [CrossRef]

10. Liang, W.; Ma, X.; Wan, P.; Liu, L. Plant salt-tolerance mechanism: A review. Biochem. Biophys. Res. Commun. 2018, 495, $286-291$. [CrossRef]

11. Khaleda, L.; Park, H.J.; Yun, D.-J.; Jeon, J.-R.; Kim, M.G.; Cha, J.-Y.; Kim, W.-Y. Humic Acid Confers HIGH-AFFINITY K+ TRANSPORTER 1-Mediated Salinity Stress Tolerance in Arabidopsis. Mol. Cells 2017, 40, 966-975. [PubMed]

12. Cha, J.-Y.; Kang, S.-H.; Ali, I.; Lee, S.C.; Ji, M.G.; Jeong, S.Y.; Shin, G.-I.; Kim, M.G.; Jeon, J.-R.; Kim, W.-Y. Humic acid enhances heat stress tolerance via transcriptional activation of Heat-Shock Proteins in Arabidopsis. Sci. Rep. 2020, 10, 1-12. [CrossRef] [PubMed]

13. Jacob, P.; Hirt, H.; Bendahmane, A. The heat-shock protein/chaperone network and multiple stress resistance. Plant Biotechnol. J. 2017, 15, 405-414. [CrossRef] [PubMed]

14. Cha, J.-Y.; Kim, T.-W.; Choi, J.H.; Jang, K.-S.; Khaleda, L.; Kim, W.-Y.; Jeon, J.-R. Fungal Laccase-Catalyzed Oxidation of Naturally Occurring Phenols for Enhanced Germination and Salt Tolerance ofArabidopsis thaliana: A Green Route for Synthesizing Humic-like Fertilizers. J. Agric. Food Chem. 2017, 65, 1167-1177. [CrossRef]

15. Saleki, R.; Young, P.G.; Lefebvre, D.D. Mutants of Arabidopsis thaliana Capable of Germination under Saline Conditions. Plant Physiol. 1993, 101, 839-845. [CrossRef]

16. Laila Khaleda; Min Gab Kim; Woe-Yeon Kim; Jong-Rok Jeon; Joon-Yung Cha Humic Acid and Synthesized Humic Mimic Promote the Growth of Italian Ryegrass. J. Korean Soc. Grassl. Forage Sci. 2017, 37, 242-247. [CrossRef]

17. Pinton, R.; Cesco, S.; Iacolettig, G.; Astolfi, S.; Varanini, Z. Modulation of NO3- uptake by water-extractable humic substances: Involvement of root plasma membrane H+ATPase. Plant Soil 1999, 215, 155-161. [CrossRef]

18. Canellas, L.P.; Olivares, F.L.; Okorokova-Façanha, A.L.; Façanha, A.R. Humic Acids Isolated from Earthworm Compost Enhance Root Elongation, Lateral Root Emergence, and Plasma Membrane H+-ATPase Activity in Maize Roots. Plant Physiol. 2002, 130, 1951-1957. [CrossRef]

19. Quaggiotti, S.; Ruperti, B.; Pizzeghello, D.; Francioso, O.; Tugnoli, V.; Nardi, S. Effect of low molecular size humic substances on nitrate uptake and expression of genes involved in nitrate transport in maize (Zea mays L.). J. Exp. Bot. 2004, 55, 803-813. [CrossRef]

20. Russell, L.; Stokes, A.R.; Macdonald, H.; Muscolo, A.; Nardi, S. Stomatal Responses to Humic Substances and Auxin are Sensitive to Inhibitors of Phospholipase A2. Plant Soil 2006, 283, 175-185. [CrossRef] 
21. Du, Z.; Zhou, X.; Ling, Y.; Zhang, Z.; Su, Z. agriGO: A GO analysis toolkit for the agricultural community. Nucleic Acids Res. 2010, 38, W64-W70. [CrossRef] [PubMed]

22. Casal, J.J.; Candia, A.N.; Sellaro, R. Light perception and signalling by phytochrome A. J. Exp. Bot. 2013, 65, 2835-2845. [CrossRef] [PubMed]

23. Yang, S.W.; Jang, I.-C.; Henriques, R.; Chua, N. FAR-RED ELONGATED HYPOCOTYL1 and FHY1-LIKE Associate with the Arabidopsis Transcription Factors LAF1 and HFR1 to Transmit Phytochrome A Signals for Inhibition of Hypocotyl Elongation. Plant Cell 2009, 21, 1341-1359. [CrossRef] [PubMed]

24. Tang, W.; Ji, Q.; Huang, Y.; Jiang, Z.; Bao, M.; Wang, H.; Lin, R. FAR-RED ELONGATED HYPOCOTYL3 and FAR-RED IMPAIRED RESPONSE1 Transcription Factors Integrate Light and Abscisic Acid Signaling in Arabidopsis. Plant Physiol. 2013, 163, 857-866. [CrossRef] [PubMed]

25. Schepens, I.; Boccalandro, H.E.; Kami, C.; Casal, J.J.; Fankhauser, C. Phytochrome kinase Substrate4 modulates phytochromemediated control of hypocotyl growth orientation. Plant Physiol. 2008, 147, 661-671. [CrossRef] [PubMed]

26. Muñoz-Nortes, T.; Pérez-Pérez, J.M.; Sarmiento-Mañús, R.; Candela, H.; Micol, J.L. Deficient glutamate biosynthesis triggers a concerted upregulation of ribosomal protein genes in Arabidopsis. Sci. Rep. 2017, 7, 1-14. [CrossRef]

27. Xu, Y.-H.; Liu, R.; Yan, L.; Liu, Z.-Q.; Jiang, S.-C.; Shen, Y.-Y.; Wang, X.-F.; Zhang, D.-P. Light-harvesting chlorophyll a/b-binding proteins are required for stomatal response to abscisic acid in Arabidopsis. J. Exp. Bot. 2011, 63, 1095-1106. [CrossRef]

28. Koini, M.A.; Alvey, L.; Allen, T.; Tilley, C.A.; Harberd, N.P.; Whitelam, G.C.; Franklin, K.A. High Temperature-Mediated Adaptations in Plant Architecture Require the bHLH Transcription Factor PIF4. Curr. Biol. 2009, 19, 408-413. [CrossRef]

29. Gururani, M.A.; Venkatesh, J.; Tran, L.P. Regulation of Photosynthesis during Abiotic Stress-Induced Photoinhibition. Mol. Plant 2015, 8, 1304-1320. [CrossRef]

30. Morrow, G.; Hightower, L.E.; Tanguay, R.M. Small heat shock proteins: Big folding machines. Cell Stress Chaperones 2014, 20, 207-212. [CrossRef]

31. Sun, W.; Bernard, C.; Van De Cotte, B.; Van Montagu, M.; Verbruggen, N. At-HSP17.6A, encoding a small heat-shock protein in Arabidopsis, can enhance osmotolerance upon overexpression. Plant J. 2001, 27, 407-415. [CrossRef] [PubMed]

32. Ohama, N.; Sato, H.; Shinozaki, K.; Yamaguchi-Shinozaki, K. Transcriptional Regulatory Network of Plant Heat Stress Response. Trends Plant Sci. 2017, 22, 53-65. [CrossRef] [PubMed]

33. Yoshida, T.; Sakuma, Y.; Todaka, D.; Maruyama, K.; Qin, F.; Mizoi, J.; Kidokoro, S.; Fujita, Y.; Shinozaki, K.; Yamaguchi-Shinozaki, K. Functional analysis of an Arabidopsis heat-shock transcription factor HsfA3 in the transcriptional cascade downstream of the DREB2A stress-regulatory system. Biochem. Biophys. Res. Commun. 2008, 368, 515-521. [CrossRef]

34. Chi, W.-T.; Fung, R.W.M.; Liu, H.-C.; Hsu, C.-C.; Charng, Y.-Y. Temperature-induced lipocalin is required for basal and acquired thermotolerance inArabidopsis. Plant Cell Environ. 2009, 32, 917-927. [CrossRef] [PubMed]

35. Abo-Ogiala, A.; Carsjens, C.; Diekmann, H.; Fayyaz, P.; Herrfurth, C.; Feussner, I.; Polle, A. Temperature-induced lipocalin (TIL) is translocated under salt stress and protects chloroplasts from ion toxicity. J. Plant Physiol. 2014, 171, 250-259. [CrossRef] [PubMed]

36. Niu, M.; Huang, Y.; Sun, S.; Sun, J.; Cao, H.; Shabala, S.; Bie, Z. Root respiratory burst oxidase homologue-dependent H2O2 production confers salt tolerance on a grafted cucumber by controlling Na+ exclusion and stomatal closure. J. Exp. Bot. 2018, 69, 3465-3476. [CrossRef] [PubMed]

37. Meyer, Y.; Belin, C.; Delorme-Hinoux, V.; Reichheld, J.-P.; Riondet, C. Thioredoxin and Glutaredoxin Systems in Plants: Molecular Mechanisms, Crosstalks, and Functional Significance. Antioxid. Redox Signal. 2012, 17, 1124-1160. [CrossRef]

38. Patterson, K.; Walters, L.A.; Cooper, A.M.; Olvera, J.G.; Rosas, M.A.; Rasmusson, A.G.; Escobar, M.A. Nitrate-Regulated Glutaredoxins Control Arabidopsis Primary Root Growth. Plant Physiol. 2015, 170, 989-999. [CrossRef]

39. Jung, J.-Y.; Ahn, J.H.; Schachtman, D.P. CC-type glutaredoxins mediate plant response and signaling under nitrate starvation in Arabidopsis. BMC Plant Biol. 2018, 18, 281. [CrossRef]

40. Deavall, D.G.; Martin, E.A.; Horner, J.M.; Roberts, R.A. Drug-Induced Oxidative Stress and Toxicity. J. Toxicol. $2012,2012,1-13$. [CrossRef]

41. Sappl, P.G.; Carroll, A.J.; Clifton, R.; Lister, R.; Whelan, J.; Millar, A.H.; Singh, K.B. The Arabidopsis glutathione transferase gene family displays complex stress regulation and co-silencing multiple genes results in altered metabolic sensitivity to oxidative stress. Plant J. 2009, 58, 53-68. [CrossRef] [PubMed]

42. Kumar, S.; Trivedi, P.K. Glutathione S-Transferases: Role in Combating Abiotic Stresses Including Arsenic Detoxification in Plants. Front. Plant Sci. 2018, 9, 751. [CrossRef] [PubMed]

43. Kovinich, N.; Kayanja, G.; Chanoca, A.; Otegui, M.S.; Grotewold, E. Abiotic stresses induce different localizations of anthocyanins in Arabidopsis. Plant Signal. Behav. 2015, 10, e1027850. [CrossRef] [PubMed]

44. Commisso, M.; Toffali, K.; Strazzer, P.; Stocchero, M.; Ceoldo, S.; Baldan, B.; Levi, M.; Guzzo, F. Impact of Phenylpropanoid Compounds on Heat Stress Tolerance in Carrot Cell Cultures. Front. Plant Sci. 2016, 7, 1439. [CrossRef] [PubMed]

45. Woo, H.R.; Kim, J.H.; Gil Nam, H.; Lim, P.O. The Delayed Leaf Senescence Mutants of Arabidopsis, ore1, ore3, and ore9 are Tolerant to Oxidative Stress. Plant Cell Physiol. 2004, 45, 923-932. [CrossRef] [PubMed]

46. Blanvillain, R.; Kim, J.H.; Wu, S.; Lima, A.; Ow, D.W. OXIDATIVE STRESS 3 is a chromatin-associated factor involved in tolerance to heavy metals and oxidative stress. Plant J. 2009, 57, 654-665. [CrossRef] [PubMed]

47. Volkov, R.A.; Panchuk, I.I.; Mullineaux, P.M.; Schöffl, F. Heat stress-induced H2O2 is required for effective expression of heat shock genes in Arabidopsis. Plant Mol. Biol. 2006, 61, 733-746. [CrossRef] [PubMed] 
48. Du, J.; Huang, Y.-P.; Xi, J.; Cao, M.-J.; Ni, W.-S.; Chen, X.; Zhu, J.; Oliver, D.J.; Xiang, C.-B. Functional gene-mining for salt-tolerance genes with the power of Arabidopsis. Plant J. 2008, 56, 653-664. [CrossRef]

49. Luhua, S.; Ciftci-Yilmaz, S.; Harper, J.; Cushman, J.; Mittler, R. Enhanced Tolerance to Oxidative Stress in Transgenic Arabidopsis Plants Expressing Proteins of Unknown Function. Plant Physiol. 2008, 148, 280-292. [CrossRef]

50. Jung, Y.J.; Melencion, S.M.B.; Lee, E.S.; Park, J.H.; Alinapon, C.V.; Oh, H.T.; Yun, D.-J.; Chi, Y.H.; Lee, S.Y. Universal Stress Protein Exhibits a Redox-Dependent Chaperone Function in Arabidopsis and Enhances Plant Tolerance to Heat Shock and Oxidative Stress. Front. Plant Sci. 2015, 6, 1141. [CrossRef]

51. Melencion, S.M.B.; Chi, Y.H.; Pham, T.T.; Paeng, S.K.; Wi, S.D.; Lee, C.; Ryu, S.W.; Koo, S.S.; Lee, S.Y. RNA Chaperone Function of a Universal Stress Protein in Arabidopsis Confers Enhanced Cold Stress Tolerance in Plants. Int. J. Mol. Sci. 2017, 18, 2546. [CrossRef] [PubMed]

52. Shi, H.; Liu, W.; Yao, Y.; Wei, Y.; Chan, Z. Alcohol dehydrogenase 1 (ADH1) confers both abiotic and biotic stress resistance in Arabidopsis. Plant Sci. 2017, 262, 24-31. [CrossRef] [PubMed]

53. Appelhagen, I.; Thiedig, K.; Nordholt, N.; Schmidt, N.; Huep, G.; Sagasser, M.; Weisshaar, B. Update on transparent testa mutants from Arabidopsis thaliana: Characterisation of new alleles from an isogenic collection. Planta 2014, 240, 955-970. [CrossRef]

54. Sagasser, M.; Lu, G.-H.; Hahlbrock, K.; Weisshaar, B.A. thaliana TRANSPARENT TESTA 1 is involved in seed coat development and defines the WIP subfamily of plant zinc finger proteins. Genes Dev. 2002, 16, 138-149. [CrossRef] [PubMed]

55. Yonekura-Sakakibara, K.; Tohge, T.; Niida, R.; Saito, K. Identification of a Flavonol 7-O-Rhamnosyltransferase Gene Determining Flavonoid Pattern in Arabidopsis by Transcriptome Coexpression Analysis and Reverse Genetics. J. Biol. Chem. 2007, 282, 14932-14941. [CrossRef]

56. Wang, G.; Ellendorff, U.; Kemp, B.; Mansfield, J.W.; Forsyth, A.; Mitchell, K.; Bastas, K.; Liu, C.-M.; Woods-Tör, A.; Zipfel, C.; et al. A Genome-Wide Functional Investigation into the Roles of Receptor-Like Proteins in Arabidopsis. Plant Physiol. 2008, 147, 503-517. [CrossRef]

57. Andersson, M.X.; Hamberg, M.; Kourtchenko, O.; Brunnström, Å.; McPhail, K.L.; Gerwick, W.H.; Göbel, C.; Feussner, I.; Ellerström, M. Oxylipin Profiling of the Hypersensitive Response inArabidopsis thaliana. J. Biol. Chem. 2006, $281,31528-31537$. [CrossRef]

58. Ma, Q.-H. Monocot chimeric jacalins: A novel subfamily of plant lectins. Crit. Rev. Biotechnol. 2014, 34, 300-306. [CrossRef]

59. Alvarez, A.; Montesano, M.; Schmelz, E.A.; De León, I.P. Activation of Shikimate, Phenylpropanoid, Oxylipins, and Auxin Pathways in Pectobacterium carotovorum Elicitors-Treated Moss. Front. Plant Sci. 2016, 7, 328. [CrossRef]

60. Iida, K.; Seki, M.; Sakurai, T.; Satou, M.; Akiyama, K.; Toyoda, T.; Konagaya, A.; Shinozaki, K. RARTF: Database and Tools for Complete Sets of Arabidopsis Transcription Factors. DNA Res. 2005, 12, 247-256. [CrossRef]

61. Han, G.; Wang, M.; Yuan, F.; Sui, N.; Song, J.; Wang, B. The CCCH zinc finger protein gene AtZFP1 improves salt resistance in Arabidopsis thaliana. Plant Mol. Biol. 2014, 86, 237-253. [CrossRef]

62. Bogamuwa, S.; Jang, J.-C. Plant Tandem CCCH Zinc Finger Proteins Interact with ABA, Drought, and Stress Response Regulators in Processing-Bodies and Stress Granules. PLOS ONE 2016, 11, e0151574. [CrossRef]

63. Park, H.-Y.; Seok, H.-Y.; Woo, D.-H.; Lee, S.-Y.; Tarte, V.N.; Lee, E.-H.; Lee, C.-H.; Moon, Y.-H. AtERF71/HRE2 transcription factor mediates osmotic stress response as well as hypoxia response in Arabidopsis. Biochem. Biophys. Res. Commun. 2011, 414, 135-141. [CrossRef]

64. Dai, S.; Wei, X.; Pei, L.; Thompson, R.L.; Liu, Y.; Heard, J.E.; Ruff, T.G.; Beachy, R.N. BROTHER OF LUX ARRHYTHMO Is a Component of the Arabidopsis Circadian Clock. Plant Cell 2011, 23, 961-972. [CrossRef]

65. Shin, J.M.; Chung, K.; Sakamoto, S.; Kojima, S.; Yeh, C.-M.; Ikeda, M.; Mitsuda, N.; Ohme-Takagi, M. The chimeric repressor for the GATA4 transcription factor improves tolerance to nitrogen deficiency in Arabidopsis. Plant Biotechnol. 2017, 34, 151-158. [CrossRef]

66. Shuai, B.; Reynaga-Peña, C.G.; Springer, P.S. The Lateral Organ Boundaries Gene Defines a Novel, Plant-Specific Gene Family. Plant Physiol. 2002, 129, 747-761. [CrossRef]

67. Gan, Y.; Bernreiter, A.; Filleur, S.; Abram, B.; Forde, B.G. Overexpressing the ANR1 MADS-Box Gene in Transgenic Plants Provides New Insights into its Role in the Nitrate Regulation of Root Development. Plant Cell Physiol. 2012, 53, 1003-1016. [CrossRef]

68. Shi, M.-Z. Biosynthesis and Metabolic Engineering of Anthocyanins in Arabidopsis thaliana. Recent Patents Biotechnol. 2014, 8 , 47-60. [CrossRef]

69. Besseau, S.; Li, J.; Palva, E.T. WRKY54 and WRKY70 co-operate as negative regulators of leaf senescence in Arabidopsis thaliana. J. Exp. Bot. 2012, 63, 2667-2679. [CrossRef]

70. Liang, Y.S.; Ermawati, N.; Cha, J.-Y.; Jung, M.H.; Su'Udi, M.; Kim, M.G.; Ha, S.-H.; Park, C.-G.; Son, D. Overexpression of an AP2/ERF-type transcription factor CRF5 confers pathogen resistance to arabidopsis plants. J. Korean Soc. Appl. Biol. Chem. 2010, 53, 142-148. [CrossRef]

71. Raines, T.; Shanks, C.; Cheng, C.-Y.; McPherson, D.; Argueso, C.T.; Kim, H.J.; Franco-Zorrilla, J.M.; López-Vidriero, I.; Solano, R.; Vaňková, R.; et al. The cytokinin response factors modulate root and shoot growth and promote leaf senescence in Arabidopsis. Plant J. 2016, 85, 134-147. [CrossRef]

72. Malcolm, R.L.; MacCarthy, P. Limitations in the use of commercial humic acids in water and soil research. Environ. Sci. Technol. 1986, 20, 904-911. [CrossRef] 
73. Ni, Z.; Kim, E.-D.; Ha, M.; Lackey, E.; Liu, J.; Zhang, Y.; Sun, Q.; Chen, Z.J. Altered circadian rhythms regulate growth vigour in hybrids and allopolyploids. Nat. Cell Biol. 2008, 457, 327-331. [CrossRef]

74. Benjamini, Y.; Hochberg, Y. Controlling the False Discovery Rate-A Practical and Powerful Approach to Multiple Testing. J. R. Stat. Soc. Ser. B-Methodol. 1995, 57, 289-300. [CrossRef]

75. Tian, T.; Liu, Y.; Yan, H.; You, Q.; Yi, X.; Du, Z.; Xu, W.; Su, Z. agriGO v2.0: A GO analysis toolkit for the agricultural community, 2017 update. Nucleic Acids Res. 2017, 45, W122-W129. [CrossRef]

76. Fisher, R.A. On the Interpretation of $\chi 2$ from Contingency Tables, and the Calculation of P. J. R. Stat. Soc. 1922, 85, 87. [CrossRef] 